\title{
Identification of new DNA markers close to the myotonic dystrophy locus
}

\author{
J D Brook, H G Harley, K V Walsh, S A Rundle, M J Siciliano, \\ P S Harper, D J Shaw
}

\begin{abstract}
The most useful markers for the prenatal diagnosis of myotonic dystrophy (DM) are APOC2 and $C K M$, both of which map proximal to $D M$. In order to produce other markers useful for DM, we have screened genomic DNA libraries constructed from cell line 20XP3542-1-4, which contains 20 to $30 \mathrm{Mb}$ of human material including $A P O C 2$ and $C K M$. Of 51 human clones identified, seven map to chromosome 17 , four to chromosome 8 , and nine to chromosome 19, and the remaining 31 were excluded from chromosome 19 but not localised further. Four of the clones from chromosome 19 map distal to $C K M$ and two of these clones (D19S62 and $D 19 S 63$ ) are closely linked to $D M$. Analysis of a family in which a crossover between $C K M$ and $D M$ has occurred shows that neither D19S62 nor D19S63 and DM have recombined, suggesting that D19S62 and D19S63 are either closer to or flanking $D M$ in relation to $C K M$. Pulsed field gel analysis showed that $C K M, D 19 S 62$, and D19S63 map to a region of at least $1500 \mathrm{~kb}$.
\end{abstract}

Myotonic dystrophy (DM) is the most common adult form of muscular dystrophy. ${ }^{1}$ It is an autosomal

Institute of Medical Genetics, University of Wales College of Medicine, Heath Park, Cardiff CF4 4XN. J D Brook*, H G Harley, K V Walsh, S A Rundle, P S Harper, D J Shaw

Department of Genetics, University of Texas, MD Anderson Hospital and Tumor Institute, Houston, Texas, USA.

M J Siciliano

Correspondence to Dr Shaw.

*Present address: Center for Cancer Research, Massachusetts Institute of Technology, Cambridge, Massachusetts, USA.

Received for publication 16 July 1990.

Revised version accepted for publication 15 August 1990.

Note: $\mathrm{APOC} 2=$ apolipoprotein $\mathrm{C} 2 . \mathrm{BCL} 3=\mathrm{B}$ cell chronic lymphocytic leukaemia/lymphoma 3 related sequence. $\mathrm{CKM}=$ creatine kinasemuscle form ( $3^{\prime}$ subclone). $\mathrm{CGB}=$ Chorionic gonadotrophin $\mathrm{B}$. ERCC1 = excision repair complementing defective repair in Chinese hamster cells 1 , complementation group 2 . FTL $=$ ferritin light chain dominant condition with a prevalence of 1 in 8000 . The DM gene is located on the long arm of chromosome 19 within the interval 19q13.2-19q13.3. Recently, a consensus order for markers in this region has emerged, which reads from centromere to telomere: BCL3-APOC2-CKM-ERCC1-DM-D19S50 $D 19 S 22 .^{2-5}$ On the proximal side of $D M, C K M$ and $E R C C 1$ map to the same $300 \mathrm{~kb}$ NotI fragment. ${ }^{6}$ For $E R C C 1$ few linkage data are available, as no conventional RFLPs have been documented. CKM is closely linked to $D M$ with a $\theta \max$ of $0.02(\mathrm{Zmax}=$ $22 \cdot 20$ ) and a -1 lod support interval of 0 to $0 \cdot 05$. On the distal side of $D M$ the closest linked marker is $D 19 S 50\left(\theta \max =0.09, \mathrm{Zmax}=15 \cdot 45^{4}\right)$. Clearly there is a need for more closely linked markers on the distal side of $D M$, in order to define the smallest genomic region in which the gene must be located.

Somatic cell hybrids WILFM2 ${ }^{7}$ and $908 \mathrm{~K}^{8}$ have been used to make genomic libraries from which many DNA markers on chromosome 19 have been identified. ${ }^{2910}$ Neither of these cell lines contains $E R C C 1$ nor markers mapping distal to it, and are thus unlikely to contain the DM locus. Hybrid cell line $20 \times P 3542-1-4^{11}$ contains approximately 20 to 30 megabases of human DNA present as one contiguous piece, translocated onto a hamster chromosome. ${ }^{12}$ Markers $B C L 3, A P O C 2, C K M$, and $E R C C 1$ are present in this hybrid whereas distal $19 \mathrm{q}$ markers $C G B$ and $F T L$ are absent. ${ }^{11}$ In view of the small amount of human material present in 20XP3542-1-4 and because it contains markers which are closely linked to $D M$, we have constructed and screened libraries from this cell line. Nine phage which map to chromosome 19 were isolated and, of these, four map distal to $E R C C 1$. We have identified restriction fragment length polymorphisms (RFLPs) with three of the markers and report linkage analysis between two of these (D19S62 and D19S63) and markers on 19q including $D M$. The relationships between the new markers and $C K M$ and $E R C C l$ were also investigated by pulsed field gel electrophoresis.

\section{Methods}

DNA TECHNIQUES

Southern blotting and filter hybridisations were performed according to standard procedures. $^{13}$ 


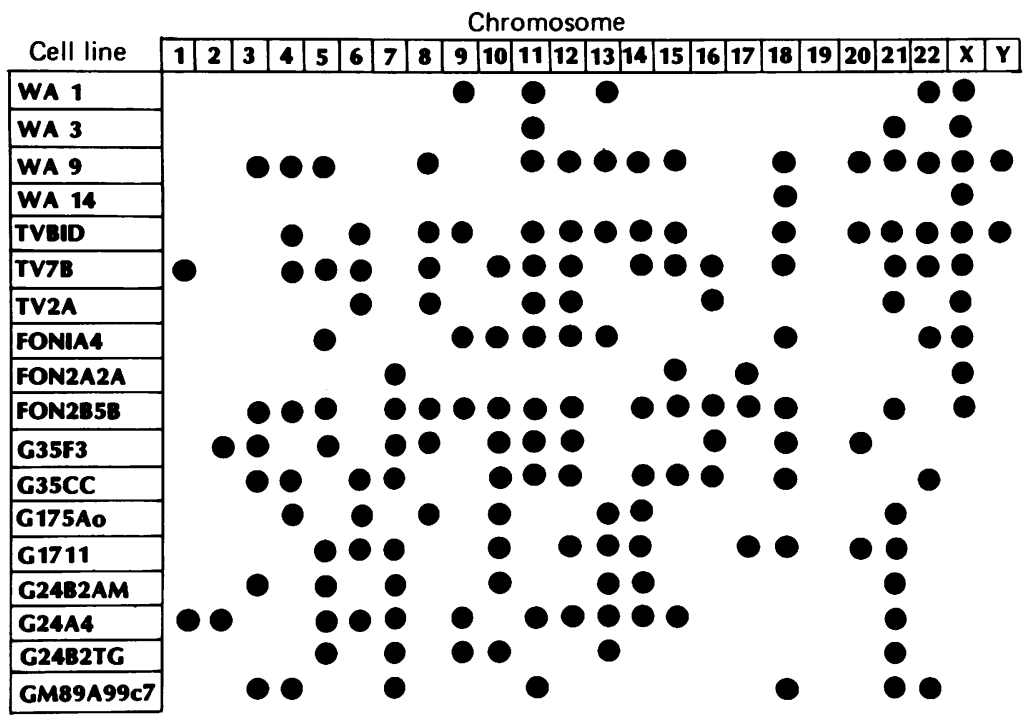

Figure 1 The chromosome content of the somatic cell hybrid panel used in this study. Hybrids in the bottom half(from $G 35 F 3$ down) contain $t(X ; 19)$ translocations and the $X$ chromosome content is $X q 24-X q t e r$ for $G 35 F 3, G 35 C C, G 175 A o$, and G1711, Xpter-Xqter for GM89A99c7, and Xq12-Xqter for G24B2AM. G24B2TG lacks the $t(X ; 19)$ chromosome. G35F3, $G 35 C C, G 175 A o$, and G1711 contain the pter-q13.2 region of chromosome 19, and GM89A99c7 contains the reciprocal part of the same translocation (19q13.3-19qter). G24B2AM contains 19p13.2-19qter. TVBID contains a $t(1 ; 19)$ retaining the region 19q12-19qter; TV7B contains the reciprocal part of the same translocation (19pter-19q12) and TV2A contains a fragment of 19 derived from the translocation chromosome. ${ }^{20}$ FON1A4 contains a different $t(1 ; 19)$ and retains most of $19 q$ including D19S9 and all markers distal; FON2BSB contains the reciprocal part of the same translocation (Brook et al, submitted).

Hybond-N (Amersham) nylon membrane was treated according to the manufacturer's instructions. Labelling of probes was performed according to the method of Feinberg and Vogelstein ${ }^{14}$ using a commercial kit (Amersham). Probes containing human repeat sequences were preannealed with a 1000 -fold excess of sheared, unlabelled, human DNA.

\section{SOMATIC CELL HYBRIDS}

The chromosome content of the somatic cell hybrids used in this study is illustrated diagramatically in fig 1. Hybrids WA1, WA3, WA9, and WA14 are described in Worwood et al, ${ }^{15}$ and hybrids TVB1D, TV7B, and TV2A are described in Brook et al. ${ }^{7}$ Hybrids G35F3, G35CC, G24B2AM, G175AOXi, G24B2TG, G1711, and G24A4 were kindly provided by Dr Gail Bruns, Boston, MA, and are described by Brook et al. ${ }^{16}$ Hybrid GM89A99c7 ${ }^{16}$ was a gift from Dr B Hellkuhl (Munster, Germany). Hybrids FON1A4, FON2A2A, and FON2B5B are described in Brook et al (submitted). Hybrid WILFM2 is described by Brook et $a l^{7}$ and 5HL9-4 was kindly provided by $\mathrm{Dr} \mathrm{L}$ Thompson (Lawrence Livermore Laboratory, USA) and contains a single human chromosome 19. For rodent controls, RAG (mouse) and Wg 3 h (hamster) cell lines were used.
LIBRARY CONSTRUCTION AND SCREENING

Two libraries were constructed with DNA from hybrid cell line 20XP3542-1-4 and screened for human sequences. For library I cell line DNA was digested to completion with $E c o R I$, fractionated on a $0.6 \%$ low melting point agarose gel, and the 15 to 22 kb fraction excised. This DNA was recovered and ligated into the EcoRI site of lambda EMBL3. Library II was constructed in a similar manner except that the cell line DNA was partially digested with $M b o I$ such that most of the DNA was in the 15 to 22 $\mathrm{kb}$ size range. This was recovered and ligated into the BamHI site of lambda EMBL3. Each library was plated out on bacterial strain NM646, blotted onto Hybond-N (Amersham) nylon filters, and screened with labelled total human DNA. Positive clones were rescreened, plaque purified, and DNA minipreps performed. ${ }^{13}$ For each clone single copy fragments were identified and used as probes in hybridisations to Southern blots of hybrid cell line DNA for chromosomal localisation.

PULSED FIELD GEL ELECTROPHORESIS

DNA samples were prepared in agarose blocks, digested with rare cutter restriction enzymes, and 
electrophoresed on a Biorad CHEF pulsed field gel apparatus, as described previously. ${ }^{17}$

\section{LINKAGE ANALYSIS}

The linkage relationship of D19S62,D19S63, and

Table 1 The primary location of clones from 20XP3542-1-4 libraries.

\begin{tabular}{lccccc}
\hline & \multicolumn{5}{c}{ Group } \\
\cline { 2 - 6 } Hybrid & A & B & C & D & E \\
\hline G35F3 & - & + & + & - & - \\
WILFM2 & - & - & + & - & + \\
GM89A99c7 & - & - & - & + & - \\
Library I (EcoRI) & 12 & 3 & 4 & 3 & 0 \\
Library II $(M b o I)$ & 19 & 6 & 2 & 1 & 1 \\
Total phage & 31 & 9 & 6 & 4 & 1
\end{tabular}

+indicates the presence of human clone in a particular hybrid.

-indicates that it is absent.

The chromosome content of G35F3 and GM89A99c7 is given in fig 1 . WILFM2 contains a single chromosome of human origin, with material derived from 19q12-19q13.2 and two other chromosomes.

Table 2 Further localisation of markers in each of the primary panel groups.

\begin{tabular}{|c|c|c|c|}
\hline Group & $\begin{array}{c}\text { Probe } \\
\text { lab name }\end{array}$ & $\begin{array}{c}\text { Chromosomal } \\
\text { localisation }\end{array}$ & D segment No \\
\hline $\begin{array}{l}\text { A } \\
\text { A } \\
\text { A } \\
\text { A } \\
\text { A } \\
\text { A } \\
\text { A }\end{array}$ & $\begin{array}{l}\lambda D 26 \\
\lambda D 11 \\
\lambda D 13 \\
\lambda D 23 \\
\lambda D 50 \\
\lambda D 74 \\
\lambda D 55\end{array}$ & $\begin{array}{c}17 \\
17 \\
17 \\
17 \\
17 \\
17 \\
1 \text { or } 2^{*}\end{array}$ & $\begin{array}{l}D 17 S 243 \\
D 17 S 244 \\
D 17 S 245 \\
D 17 S 246 \\
D 17 S 247 \\
D 17 S 249\end{array}$ \\
\hline $\begin{array}{l}\text { B } \\
\text { B } \\
\text { B } \\
\text { B } \\
\text { B }\end{array}$ & $\begin{array}{l}\lambda D 19 \\
\lambda D 38 \\
\lambda D 48 \\
\lambda D 47 \\
\lambda D 43\end{array}$ & $\begin{array}{c}8 \\
8 \\
8 \\
8 \\
1 \text { or } 2^{*}\end{array}$ & $\begin{array}{l}D 8 S 80 \\
D 8 S 81 \\
D 8 S 82 \\
D 8 S 83\end{array}$ \\
\hline $\begin{array}{l}\mathrm{C} \\
\mathrm{C} \\
\mathrm{C} \\
\mathrm{C} \\
\mathrm{C} \\
\mathrm{C}\end{array}$ & $\begin{array}{l}\lambda \mathrm{D} 6 \\
\lambda \mathrm{D} 14 \\
\lambda \mathrm{D} 16 \\
\lambda \mathrm{D} 21 \\
\lambda \mathrm{D} 56 \\
\lambda \mathrm{D} 54\end{array}$ & $\begin{array}{l}19 \\
19 \\
19 \\
19 \\
19 \\
16\end{array}$ & $\begin{array}{l}D 19 S 59 \\
D 19 S 40 \\
D 19 S 41 \\
D 19 S 42 \\
D 19 S 60 \\
D 16 S 203\end{array}$ \\
\hline $\begin{array}{l}\text { D } \\
\text { D } \\
\text { D } \\
\text { D }\end{array}$ & $\begin{array}{l}\lambda \mathrm{D} 3 \\
\lambda \mathrm{D} 8 \\
\lambda \mathrm{Dl0} \\
\lambda \mathrm{D} 36\end{array}$ & $\begin{array}{l}19 \\
19 \\
19 \\
19\end{array}$ & $\begin{array}{l}D 19 S 61 \\
D 19 S 62 \\
D 19 S 63 \\
D 19 S 64\end{array}$ \\
\hline $\mathbf{E}$ & $\lambda \mathrm{D} 62$ & 17 & D17S248 \\
\hline
\end{tabular}

${ }^{*}$ Indicates provisional lncalisation. myotonic dystrophy $(D M)$ was analysed using the panel of DM families that has formed the basis of previous studies. ${ }^{18}$ Generally, only definitely affected subjects were used for the calculation of recombination fractions between $D M$ and marker loci; age at onset corrections were not used. Standard clinical criteria for the diagnosis of DM were used. Lod scores and recombination fractions were calculated using the LINKAGE programs. ${ }^{19}$

\section{Results}

Fifty-one lambda clones that contain human inserts were identified. These were divided into five groups based on their hybridisation patterns against a primary panel of three hybrid cell lines, G35F3, WILFM2, and GM89A99c7, and these data are summarised in table 1. A selection of clones from each group were hybridised against the full panel of cell lines shown in fig 1 . These fully localised clones with $D$ numbers assigned are listed in table 2 . Clones that map to groups A, B, and E of the primary panel are derived from chromosomes other than 19.

The clones on chromosome 19 localise to both sides of a breakpoint at the interface of 19q13.2-19q13.3. Fig 2 shows that clones in group $C(\lambda D 6, \lambda D 14$,

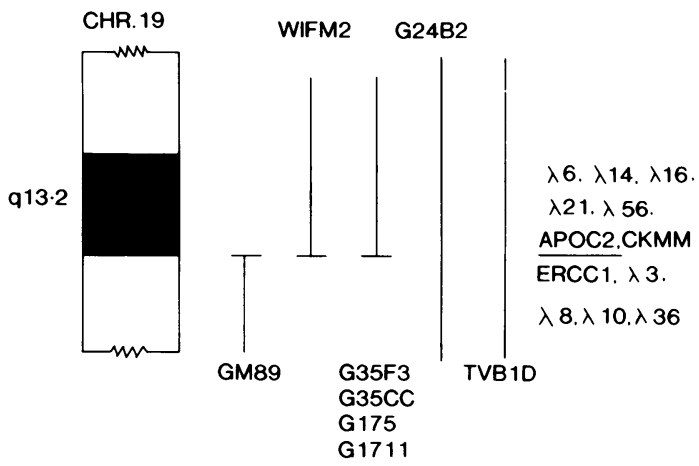

Figure 2 This shows the subchromosomal localisation on chromosome 19 of nine clones reported here, in relation to previously reported markers close to DM. The chromosome 19 content of these hybrids is 19 pter-19q13.2 for G35F3, G35CC, G175, and G1711 and 19q13.3-19qter for GM89. G24B2AM retains 19q13.2-19qter. TVB1D retains 19q12-19qter. WILFM 2 retains a fragment of $19 q$ including some of $19 q 13.1$ and 19q13.2. (GM89=GM89A99c7;WIFM2=WILFM2; $G 175=G 175 o X i=G 175 A o$ )

Table 3 Linkage analysis of D19S62 and D19S63 to DM (sexes combined).

\begin{tabular}{|c|c|c|c|c|c|c|c|c|c|c|c|c|c|}
\hline \multirow[b]{2}{*}{ Marker loci } & \multicolumn{13}{|c|}{ Lod scores $(\theta)$} \\
\hline & 0 & 0.05 & $0 \cdot 1$ & $0 \cdot 15$ & $0 \cdot 2$ & $0 \cdot 25$ & $0 \cdot 3$ & 0.35 & 0.4 & 0.45 & $\theta \max$ & $\mathrm{Z} \max$ & $\begin{array}{l}-1 \text { lod support } \\
\text { interval }\end{array}$ \\
\hline$D M-D 19 S 62$ & $8 \cdot 27$ & $9 \cdot 75$ & $8 \cdot 80$ & $7 \cdot 68$ & $6 \cdot 49$ & $5 \cdot 24$ & 3.97 & $2 \cdot 69$ & 1.50 & 0.52 & 0.02 & $10 \cdot 09$ & $\begin{array}{r}0.005 \\
-0.08\end{array}$ \\
\hline$D M-D 19 S 63$ & $14 \cdot 13$ & $19 \cdot 82$ & $17 \cdot 87$ & $15 \cdot 47$ & $12 \cdot 87$ & $10 \cdot 18$ & $7 \cdot 50$ & $4 \cdot 94$ & $2 \cdot 66$ & 0.91 & 0.02 & $20 \cdot 28$ & $\begin{array}{r}0.01 \\
-0.06\end{array}$ \\
\hline
\end{tabular}




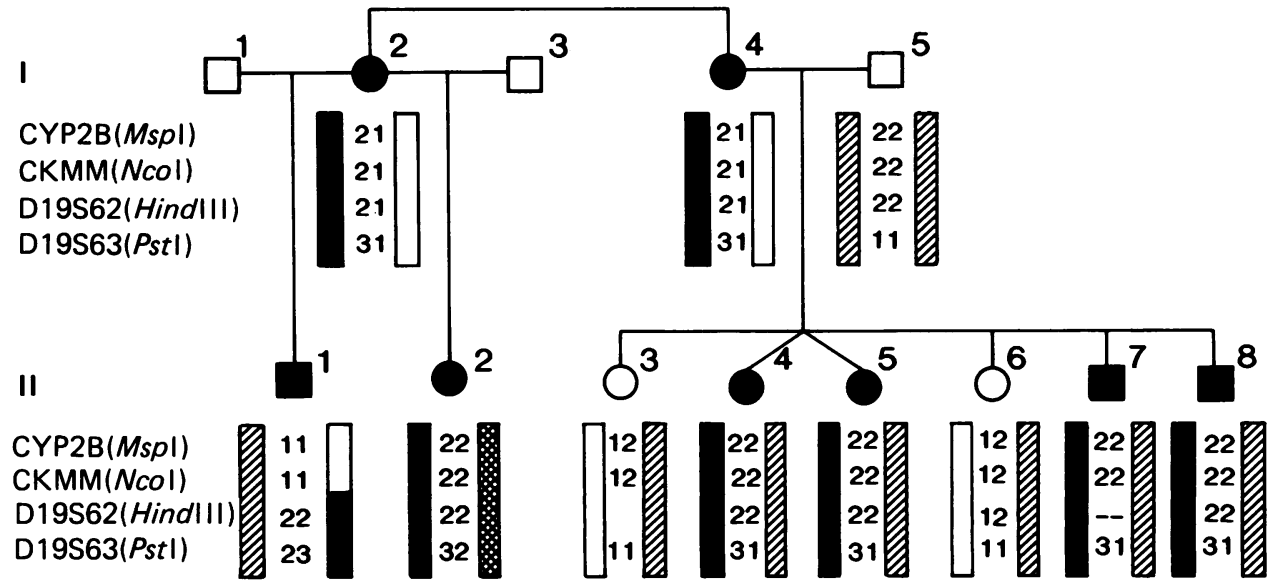

Figure 3 Pedigree of a myotonic dystrophy family, showing that in subject II 1 the markers CYP2B and CKM have recombined with DM,D19S62, and D19S63. Chromosomes carrying the DM disease allele are shown in black; normal chromosomes from the affected parent in white; and chromosomes from unaffected spouses are hatched.

$\lambda D 16, \lambda D 21$, and $\lambda D 56)$ are at $19 q 12-19 q 13.2$ whereas those in group $\mathrm{D}(\lambda \mathrm{D} 3, \lambda \mathrm{D} 8, \lambda \mathrm{D} 10$, and $\lambda \mathrm{D} 36)$ are at $19 \mathrm{q} 13.3-19 \mathrm{qter}$. Clones $\lambda \mathrm{D} 3, \lambda \mathrm{D} 8, \lambda \mathrm{D} 10$, and $\lambda \mathrm{D} 36$ were screened for RFLPs with a variety of enzymes and polymorphisms identified for $\lambda \mathrm{D} 8$ (D19S62), $\lambda \mathrm{D} 10(D 19 S 63)$, and $\lambda \mathrm{D} 36$ (D19S64). In this study, a three allele PstI RFLP for D19S63 and a two allele $H$ indIII RFLP for D19S62 were used. ${ }^{21} 22$

Linkage analysis was performed with D19S62, $D 19 S 63$, and DM in DM families. These data are shown in table 3. D19S62 is closely linked to $D M$ $(\theta \max =0.02, Z \max =10.09)$, as is D19S63 $(\theta \max =$ $0.02, \mathrm{Zmax}=20 \cdot 28)$. No obligate recombinants with either marker were observed. D19S62 and D19S63 are also closely linked to both $A P O C 2$ and $C K M$, but less closely linked to $D 19 S 22$. The data relating to the linkage of the new markers to other RFLPs on chromosome $19 q$ will be presented in full elsewhere (Harley et al, in preparation).

The segregation of D19S62 and D19S63 was examined in a family for which a crossover between $C K M$ and $D M$ has been identified. This family is shown in fig 3. Subject II 1 , who is recombinant for $C K M-D M$, is also recombinant for $C K M-D 19 S 62$ and $C K M-D 19 S 63$, but not for $D M-D 19 S 62$ or DM-D19S63.

Human and somatic cell hybrid DNA was digested with NotI or MluI, separated by CHEF electrophoresis, and probed with ERCC1, CKM, D19S62, and D19S63. ERCCI and CKM hybridise to the same $300 \mathrm{~kb}$ NotI fragment. ${ }^{6}$ D19S62 and D19S63 did not hybridise to any fragments in common with each other or with ERCC1 or CKM. D19S63 hybridised to a $200 \mathrm{~kb}$ NotI fragment, and D19S62 to a series of NotI partial digest fragments, the largest of which was $1000 \mathrm{~kb}$. Recent studies using further probes from this region have linked D19S63 to $E R C C 1$ and $C K M$, and show that the order of markers is CKM-ERCC1-D19S63-D19S62 (manuscript in preparation).

\section{Discussion}

The markers most closely linked to $D M$ are $A P O C 1$, $A P O C 2, B C L 3$, and $C K M^{5223}$ on the proximal side and pEWRB1 (D19S50) on the distal side. ${ }^{4} C K M$ and $A P O C 2$ are closely linked to $D M$ at a $\theta \max$ of 0.02 and 0.03 respectively. pEWRB1 (D19S50), which is linked to $D M$ with a $\theta \max$ of $0 \cdot 09,{ }^{4}$ is the closest marker on the distal side. In order to identify more human sequences which are useful for linkage analysis and prenatal diagnosis of DM, in particular closely linked markers on the distal side of this locus, we have constructed and screened genomic libraries from cell line 20XP3542-1-4. ${ }^{11}$ The nine clones reported here that map to chromosome 19 should be useful for further studies on DM. Four of these clones, D3 (D19S61), D8 (D19S62), D10 (D19S63), and D36 (D19S64) map distal to CKM in the interval 19q13.319qter, and are therefore potentially flanking the DM locus.

Analysis of DM families showed that D19S62 and $D 19 S 63$ are closely linked to $A P O C 2, C K M$, and $D M$. No obvious recombinants have been observed between $D 19 S 62$ or D19S63 and DM. In one family (fig 3) for which a $C K M-D M$ crossover has been observed, D19S62 and D19S63 have also recombined with $C K M$, and there is no crossover between $D 19 S 62$ or $D 19 S 63$ and $D M$. This family suggests that D19S62 and D19S63 are either closer to, or 
flanking, $D M$ in relation to $C K M$, but until recombination is detected between $D M$ and these new markers, it will not be possible to determine if either marker flanks $D M$ on the distal side.

Cell line 20XP3542-1-4 contains 20 to 30 megabases of human material. ${ }^{12} \mathrm{We}$ estimate that slightly less than $20 \%$ of this is derived from human chromosome 19 , since in the present study nine out of 51 clones mapped to 19. This 4 to $6 \mathrm{Mb}$ of chromosome 19 material can be divided into two intervals using available cell lines. Of the nine clones on chromosome 19, five map to the same interval as $C K M$ and four map distal. Thus, we estimate that cell line 20XP35421-4 contains $2 \mathrm{Mb}$ of material from chromosome 19 distal to $C K M$. Pulsed field gel analysis has shown that four of the markers studied here (CKM, ERCC1, D19S62, and D19S63) detect NotI fragments with a total length of $1.5 \mathrm{Mb}$. If we assume $1 \mathrm{cM}$ is equivalent to about $1 \mathrm{Mb}$ we would predict from the linkage analysis that $D M$ maps not more than $2 \mathrm{Mb}$ from $C K M$, quite likely within the chromosome 19 derived material in 20XP3542-1-4.

In a recent study, Johnson et $a l^{24}$ reported the construction of a cosmid library from the hybrid 20XP3542-1-4. They isolated 76 human cosmids of which $32(42 \%)$ mapped to chromosome 19 and, of these 32 , five $(16 \%)$ were derived from the region distal to $C K M$. The difference between these proportions and those obtained in the present study may be because of one or more of the following factors: different vectors and host strains; different partial digestion conditions; different hybrid cell lines used for chromosomal localisation; or random statistical fluctuation.

From existing information it is not possible to determine whether 20XP3542-1-4 contains the DM locus. Nevertheless the four clones reported here mapping distal to $C K M$ should be useful for the prenatal diagnosis of DM and in jumping and linking strategies to flank and identify the DM gene. It will also be possible to construct a complete physical map of the region and to identify HTF islands and coding sequences which would be candidates for DM.

This study was supported by the United Kingdom Muscular Dystrophy Group, the Muscular Dystrophy Association (USA), and the Wellcome Trust. We would like to thank Miss Linda Frost and Miss Lisa Cochlin for preparation of the manuscript.

1 Harper PS. Myotonic dystrophy. 2nd ed. London, Philadelphia, Saunders, 1989.

2 Harley HG, Brook JD, Rundle SA et al. A map of the long arm of chromosome 19: an order for twelve polymorphic markers and the myotonic dystrophy gene. HGMlO A2626. Cytogenet liell Genet 1989;51:1011.

3 Johnson K, Shelbourne P, Davies J, et al. Recombination events that locate myotonic dystrophy distal to APOC2 on 19q. Genomics 1989;5:746-51.

4 Korneluk RG, Mackenzie AE, Nakamura Y, Dube I, Jacob P, Hunter AGW. A reordering of human chromosome 19 long arm DNA markers and identification of markers flanking the myotonic dystrophy locus. Genomics 1989;5:596-604.

5 Brunner HG, Smeets H, Lambermon HMM, et al. A multipoint linkage map around the locus for myotonic dystrophy on chromosome 19. Genomics 1989;5:589-95.

6 Smeets $\mathrm{H}$, Bachinski L, Coerwinkel $\mathrm{M}$, et al. A long-range restriction map of the human chromosome $19 \mathrm{ql} 3$ region: close physical linkage between CKMM and the ERCCl and ERCC2 genes. Am F Hum Genet 1990;46:492-501.

7 Brook JD, Shaw DJ, Thomas NST, Meredith AL, Cowell J, Harper PS. Mapping genetic markers on human chromosome 19 using sub-chromosomal fragments in somatic cell hybrids. Cytogenet Cell Genet 1986;41:30-7.

8 Hulsebos T, Wieringa B, Hochstenbach R, et al. Toward early diagnosis of myotonic dystrophy: construction and characterisation of a somatic cell hybrid with a single human der(19) chromosome. Cytogenet Cell Genet 1986;43:47-56.

9 Shaw DJ, Meredith AL, Sarfarazi M, et al. Regional localisations and linkage relationships of seven RFLPs and myotonic dystrophy on chromosome 19. Hum Genet 1986;74:262-6.

10 Schonk D, Coerwinkel-Driessen M, Van Dalen I, et al. Definition of subchromosomal intervals around the myotonic dystrophy gene region at 19q. Genomics 1989;4:384-96.

11 Stallings RL, Olson E, Strauss AW, Thompson JH, Bachinski LL, Siciliano MJ. Human creatine kinase genes on chromosomes 15 and 19 , and proximity of the gene for the muscle form to the genes for apolipoprotein $\mathrm{C} 2$ and excision repair. $A m \mathcal{J}$ Hum Genet 1988;43:144-51.

12 Liu P, Legerski R, Siciliano MJ. Isolation of human transcribed sequences from human-rodent somatic cell hybrids. Science 1989;246:813-5.

13 Sambrook J, Fritsch EF, Maniatis T. Molecular cloning: $a$ laboratory manual. Cold Spring Harbor, NY: Cold Spring Harbor Laboratory, 1989.

14 Feinberg AP, Vogelstein B. A technique for radiolabelling DNA restriction endonuclease fragments to high specific activity. Anal Biochem 1983;132:6-13.

15 Worwood M, Brook JD, Cragg SJ, et al. Assignment of human ferritin genes to chromosomes 11 and 19q13.3-19qter. Hum Genet 1985;69:371-4.

16 Brook JD, Shaw DJ, Meredith L, Bruns GAP, Harper PS. Localisation of genetic markers and orientation of the linkage group on chromosome 19. Hum Genet 1984;68:282-5.

17 Shaw DJ, Harley HG, Brook JD, McKeithan TW. Long-range restriction map of a region of human chromosome 19 containing the apoliprotein genes, a CLL-associated translocation breakpoint, and two polymorphic Mlul sites. Hum Genet 1989;83:71-4.

18 Harley HG, Brook JD, Jackson CL, et al. Localisation of a human $\mathrm{Na}+, \mathrm{K}+-\mathrm{ATPase}$ alpha subunit gene to chromosome $19 \mathrm{q} 12-\mathrm{q} 13.2$ and linkage to the myotonic dystrophy locus. Genomics 1988;3:380-4.

19 Lathrop GM, Lalouel JM, Julier C, Ott J. Strategies for multilocus linkage analysis in humans. Proc Natl Acad Sci USA 1984;81:3443-6.

20 Brook JD, Skinner M, Roberts SH, Rettig WJ, Almond JW, Shaw DJ. Further mapping of markers around the centromere of human chromosome 19. Genomics 1987;1:320-8.

21 Brook JD, Harley HG, Rundle SA, Walsh KV, Shaw DJ. RFLP for a DNA clone which maps to 19q13.2-19qter (D19S63). Nucleic Acids Res 1990;18:1085.

22 Brook JD, Walsh KV, Harley HG, Rundle SA, Shaw DJ. A polymorphic DNA clone which maps to 19q13.2-19qter (D19S62). Nucleic Acids Res 1990;18:1086.

23 Walsh KV, Harley HG, Brook JD, et al. Linkage relationships of the apolipoprotein $\mathrm{CI}$ gene and a cytochrome p450 gene (CYP2A) to myotonic dystrophy. Hum Genet 1990;85:305-10.

24 Johnson K, Shelbourne P, Davies J, et al. A new polymorphic probe which defines the region of chromosome 19 containing the myotonic dystrophy locus. Am f Hum Genet 1990;46: 1073-81. 